九州大学学術情報リポジトリ

Kyushu University Institutional Repository

\title{
Fuzzy Decision Support System for the Outbreak of COVID-19 and Improving the People Livelihood
}

Gunasekaran Prabakaran

Department of Electronics and Communication Engineering, College of Engineering Guindy, Anna University

Dhandapani Vaithiyanathan

Department of Electronics and Communication Engineering, National Institute of Technology Delhi

Harish Kumar

Department of Mechanical Engineering, National Institute of Technology Delhi

https://doi.org/10.5109/4372258

出版情報 : Evergreen. 8 (1)，pp.36-43，2021-03. 九州大学グリーンテクノロジー研究教育センター バージョン：

権利関係 : 


\title{
Fuzzy Decision Support System for the Outbreak of COVID-19 and Improving the People Livelihood
}

\author{
Gunasekaran Prabakaran¹, Dhandapani Vaithiyanathan², Harish Kumar ${ }^{3, *}$ \\ ${ }^{1}$ Department of Electronics and Communication Engineering, College of Engineering Guindy, \\ Anna University, India \\ ${ }^{2}$ Department of Electronics and Communication Engineering, National Institute of Technology Delhi, Delhi, \\ India. \\ ${ }^{3}$ Department of Mechanical Engineering, National Institute of Technology Delhi, Delhi, \\ India.
}

*Author to whom correspondence should be addressed:

E-mail: harishkumar@nitdelhi.ac.in

(Received November 9, 2020; Revised March 23, 2021; accepted March 26, 2021).

\begin{abstract}
This work investigates the process of the outbreak of the COVID-19 epidemic and makes recommendations using a fuzzy logic system. In the current situation to control COVID-19 spread, there is a need to build a system for its outbreak. Besides, when creating a system, many factors need to be considered without affecting the regular functioning of the work. Hence, this work presents a novel approach with inputs as the most important factors, including the social factors involved in the discovery of the causes of the spread of the COVID-19 virus. Assumed quantifying reasons behind in the society were believed to improve the outbreak of COVID-19 progress in the world. Hence, this work will illustrate the concept behind considering the COVID-19 outbreak system design with the support of expert recommendations. The study has been undertaken to overcome the extent of infectious diseases, to consider the workers' livelihoods in detail, and to make expert recommendations for improving the quality of life without any difficulty. Up to this point, no vaccine has been officially announced to control the outbreak of COVID-19. In this way, this paper outlines a larger mechanism to control the early stages of any pandemic disease such as Covid-19.
\end{abstract}

Keywords: COVID-19; Fuzzy Decision Support System; Skilled and Unskilled; Workers Livelihood

\section{Introduction}

A novel virus, COVID-19, has been identified in Wuhan, China, which is rapidly spreading worldwide ${ }^{1-6)}$. The curb of the COVID-19 pandemic around the world is still unresolved, due to the complexity of the virus structure and its characteristics ${ }^{7)}$. In such a situation, researchers are working to reduce the onset of the disease in different dimensions and to analyze it. Thus, results such as the evaluation of the COVID-19 kinetics and prediction of its spread are being analyzed ${ }^{8-9)}$.As per this momentum, nearly 200 countries all around the world have been affected by COIVD-19 pandemic disease infection. To avoid the community spread, all the countries are working in full swing and have followed the concept of lockdown as per the directions of WHO 10-15). The lockdown concept has also provided good results in preventing the spread of pandemics so far. At the same time, while the lockdown is in progress we have to consider the various essential factors to protect people from the COVID-19 pandemic. Given the prevailing norms in various countries around the world, the system will help to reduce the spread of COVID-19 following the guidelines of the World Health Organization, and other important guidelines that have been included ${ }^{16)}$. Whatever the case of infectious disease or other life-threatening conditions, there is a responsibility to save people and provide them with decent living possibilities ${ }^{17)}$.This responsibility is as much for the private sector as it is for the people and the government machinery. Such assistance from private companies can not only prevent the spread of the disease but also increase the responsibility of the community in the minds of the people and preserve the environment ${ }^{18)}$. The governance of the private authority, its affiliates agents and entrepreneurs has been helpful in some cases 
19). At the same time, it is necessary to take into account the different thought processes of people ${ }^{20}$. Therefore, a system has become very important for the people to live a dignified life because it is necessary for the people and the government to face the harsh conditions of the epidemic. In such a case, modeling the system to combat the epidemic has become a mandatory requirement ${ }^{21}$. Provided, it will depend on policy-related strategies or the regular functioning of the style in which people work ${ }^{22)}$. In that sense, the pioneering of policy proposals are dependent on the level of international changes, therefore the modeling of the system with existing fixtures at the current level seems to be beneficial in this pandemic. Accordingly, this research work describes the detailed structure of the proposed model, which has been established to fight pandemic disease with various real-time social parameters. In such situations the term social factor can be very useful in creating a sustainable community ${ }^{23)}$. Generally, people in the world practice different types of businesses for their livelihood. Based on this, the people living in the society are divided into two major categories: skilled workers and unskilled workers ${ }^{24-25)}$. Skilled workers are professionals with technical education backgrounds whereas, unskilled laborers are a gap of technical backgrounds except with minimum educational backgrounds. Therefore, people in both types of institutions depend on free trade to turn the wheel of their daily lives. In such extreme cases as the spread of COVID-19, the livelihoods of the entire population are in jeopardy. Hence, an organized computing platform is needed to help balance the situation on the spot or to help them with financial resources and some essential resources ${ }^{26)}$.Especially in such situations, people are most vulnerable to food shortages and exorbitant rates of essential items. This is because financial resources and social factors are deeply associated with mortality in many diseases ${ }^{27)}$. Realizing this, developing countries like India have provided financial assistance to the people of the country during the lockdown period, which provides a moderate relief against their financial plummeting ${ }^{28)}$. Since, the spread of a COVID-19 has caused a complete recession in the chain of the supply chain, starting from the lives of rural people to the lives of urban workers ${ }^{29)}$. At the same time, these factors alone do not affect the situation, which is also associated with some other variables ${ }^{30}$. Therefore, both types of institutions need a well-regulated system to protect people's lives and prevent the spread of disease. On these lines, an approach has been initiated to balance the skilled and unskilled worker's difficulties with measures to eradicate the pandemic as well as to save their livelihood. Likewise, this paper takes the assumptions of both skilled and unskilled workers' livelihoods and it has been analyzed with fuzzy logic. This research is a very complex analysis of inference data based on real-time scenarios of global worker's conditions. Furthermore, this work sets out people's livelihoods in a range of minimum requirements and provides recommendations for measures to be taken for people's livelihood in unusual circumstances such as infection, pandemics, and so on. Whilst, the paper consist of the following reasons why people came forward even when a life-threatening disease was spreading around the world. The reasons are,

1. Money

2. Essential commodities

3. Essential medicines which for already aliment diseases

4. Gender

5. Things used to take care of the children as well as aged peoples

To analyze the system design possibilities of the COVID-19 outbreak, this research is based on two levels of World workers types.

1. Skilled workers Type

2. Unskilled workers Type

Likewise, the causes mentioned are the pathways leading to the spread of COVID-19. For instance money, essential commodities, essential medicines which were already aliment diseases, gender both male and female and things to take care the children as well as older adult peoples. Gender is only approached traditionally, and the reason for the concept of heritage is that it is directly accessible based on the fact that a lot of families live under male leadership. In the absence of a male head of the family, the woman is placed in the place of the head of the family and the system is established. Further, determining the position of a family leader depends only based on their mutual similarities and it is only set to emphasize the notion that the principles of male and female equality are promoted ${ }^{31-32}$. In addition to money concerns, it is considered here to be one of the essential elements of life for a human, while none of the other factors behind the money are considered important here 33). Apart from that, the assumptions that were directly assumed by from guidelines of WHO and various other country government proceedings are against each type of reason. After building our assumptions conditions based on the currently practiced norms the assumed data were analyzed by using different types of membership functions by fuzzy logic. This is because the concepts of fuzzy logic already make a huge contribution in terms of epidemiology and epidemiological control ${ }^{34-35)}$. The concepts of fuzzy logic can build the system to reduce the COVID-19 pandemic concerns of different reasons from different assumptions and hence the system captures the schematic flexibility inherent in complex conditions or assumptions from the COVID-19 pandemic. According to the literature, various studies do not consider the difficulties and uncertainties that confront COVID-19 infections in worker's livelihoods. Therefore, the organization of this design adopted an international level of labor-oriented ideas on the status of livelihood, including skilled workers and unskilled workers. Thus 
the major contribution of this work is, depending on the people working livelihood situation, recommendations are made to governments or other aid line departments to reduce the impact of the disease and improve the livelihood of the workers.

\section{Methods and Materials}

This section provides explicit information on method adaptation. The study was conducted with a global data set of skilled and unskilled workers. It is designed with the help of world employment social outlook trends 2019 36). People's livelihoods are considered to be following a combination of world employment social outlook trends 2019 and expert recommendations. There is uncertainty in determining people's livelihoods in infectious situations, so fuzzy logic is chosen to overcome the ambiguity of the problem, and a fuzzy model system is built to eradicate the COVID-19 epidemic. The parameters to be considered here are money, essential medicines, essential commodities, gender, and essential components for children and older adults respectively.

\section{Methods and Materials}

Although the world is struggling to get rid of COVID-19, people are coming out of the house to meet their needs. Primarily, people's livelihood includes money, essentials commodities, essential medicines for diseases that have already been revamped, and a variety of factors used to care for children and elderly people. These entire primaries needs apply to both genders. Considering these two conditions, people's livelihoods are designed to be a unique site; hence they are fixed in the 0-5 range with the support of experts. This is because human life has always been socially and economically intertwined with externalities ${ }^{37)}$. Each type of variable is individually accessible, in that there is a chance to occur on slight variation in people's livelihood levels. Therefore, it has been undertaken to bring the common ground to the conditions of people's livelihoods in an integrated manner.

$$
P_{X}=\frac{\left(\int_{A V}^{N V} M O * \int_{A V}^{N V} E C^{*} \int_{A V}^{N V} E M * \int_{A V}^{N V} G * \int_{A V}^{N V} C A T G\right.}{N v . o f\left(M O * E C^{*} E M * G^{*} C A T G\right)}
$$

Where,

NV- Necessary Value

AV-Actual Value

MO-Money

EC-Essential Commodities

EM-Essential Medicine

G-Gender

CATG-Childers take cares of things and older adult people's essential things
For example, $\mathrm{Px}=0$ the pandemic is not transmitted to the community and therefore there is no need for any recommendations suggested by the system. For Other values, such as $\mathrm{Px}=1100 \%$ recommendations are needed and, $\mathrm{P}_{\mathrm{X}}>0.50$ and $\mathrm{Px}<0.50$ the system recommends $75 \%$ and $25 \%$ respectively.

\section{Decision support system design}

The COVID-19 pandemic caused a major setback to the world. Essential measures are taken by various organizations to control the infection, but the percentage of spread by virus intensity has increased day by day. In such contagious situations, fuzzy logic can be used to define out breaking sidewalks. Therefore fuzzy logic enables us to analyze all the stages of the disease positively towards the pandemic range of outcomes and provide the solution to break it down. Fuzzy logic is a concept used to determine the degree of truth in certain situations, which is an extended version of Boolean logic. This is especially the case for uncertainty and ambiguous situations. Fuzzy logic has three different types of functions in the platform. Functions labeled as fuzzification, fuzzy rule design and defuzzification. Fuzzy logic is the process of making the variable obscure and the fuzzy inference unit has the rule structure for specific applications, and the process of turning the fuzzy smooth into a numerical value is repeatable again. Generally, a decision support system is called the fuzzy system $^{38)}$. Figure 1 shows the basic fuzzy structure.

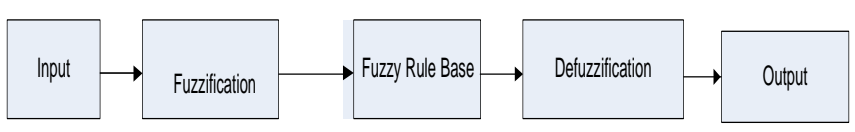

Fig. 1: Fuzzy Basic Structure

The proposed fuzzy decision support system with the expert integration of the COVID-19 outbreak strategy is presented in Figure 2. Here, Fuzzy DSS has been built from two main backgrounds. One is that the reasons of people affecting situations on a form the ground of skilled labor background and other is from in the ground of unskilled labor background. On both, the background peoples have been affected but at the same time, the affecting value has slightly differed in these two backgrounds. Whilst, the two backgrounds based fuzzy rule-designed structure has been discussed with the basic fuzzy operations of the fuzzy logic. In terms of the classification of skilled and unskilled workers, the study is categorized by the International Labor Organization as low income, low middle income, upper middle income and high income. That is, all the people in the lower-income and lower-middle-income categories are placed on the list of unskilled workers, while the upper-middle-income and high-income earners are on the list of skilled workers. This is because the knowledge 
gap between them is the only parameter to determine the income among workers. In contrast, in this work, a world labor trend may be followed as usual, but this presents additional problems for the system in the range of relief packages allocation.

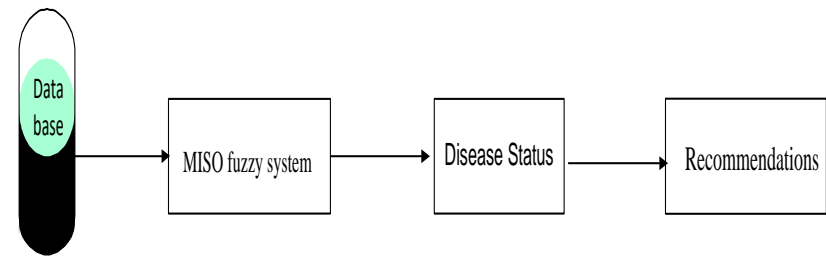

Fig. 2: Proposed Fuzzy Decision Support System Structure

The proposed DSS has been the multi-input and single-output system and too easy the system design MATLAB R2019a is used to simulate the output. The fuzzy logic controllers are extensively used for controlling the various complications of inputs and fuzzy functions labeled as fuzzification, fuzzy rule design and defuzzification. In addition to the aggregation of fuzzy rule, three types of fuzzy controllers are used like the Mamdani fuzzy system, Sugeno fuzzy system and Trukamoto system. The typical multi-input and single output fuzzy system are as follows,

\section{If Input1 is S1 and Input2 is S2 Then Output is Y1} If Input1 is $\mathrm{Z} 1$ and Input2 is $\mathrm{Z} 2$ Then Output is $\mathrm{Y} 2$

Where there are two types of things are available. 1. Input and Output variables of the fuzzy system and fuzzy sets. Input1, Input 2, and output are fuzzy system variables and $\mathrm{X} 1, \mathrm{X} 2, \mathrm{Y} 1, \mathrm{Y} 2, \mathrm{Z} 1, \mathrm{Z} 2$ are fuzzy sets. The degree of fuzzy action depends on the size of the pre-conceptual reality proposal. In this COVID-19 outbreak system design, all three fuzzy controllers are approached finally the decision support system was designed. The entire process and initiatives have been attempted with on the possibility of an outbreak the pandemic. The system is designed to take into account the difficulty of workers and suggestions with experts. Figure 3 shows the integration of the fuzzy decision support system for the outbreak of the COVID-19 epidemic, and each of the input variables and the recommended input chart focused on reducing the spread of the disease was used at the system level. As already stated, system evaluation and emergence need to COVID-19 outbreak require linguistic variables of each head membership function, which include: Money- In hand and not in hand, Essential commodities- Available or Not Available, Essential medicines which for already aliment diseases- Available or Not Available, GenderBoth Male and Female, Things used to take care the children as well as older adult peoples - Available or Not Available Target Output- Diseases transmission or Not.

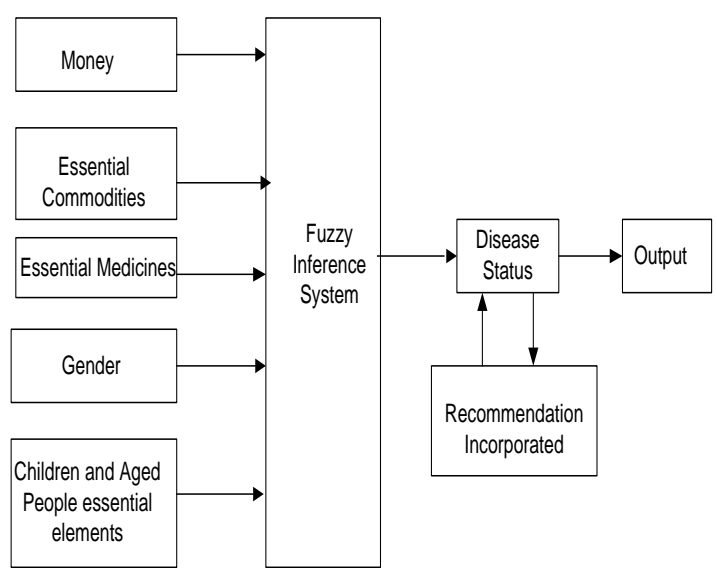

Fig. 3: Block Diagram for fuzzy decision support for COVID-19 Outbreak

\section{Fuzzification Process}

Fuzzy membership functions are developed and used in a fuzzy inference system for changing linguistic variables. The basic fuzzy logic rule is an if-then structure. Functions begin to emerge as the disease spreads into influential variables within a set of rules. Figures 4 and 5 show the membership functions of the fuzzy packages relative to the input variable of the essential commodities and the essential medicines respectively. The form of variables for membership functions between a linguistically ambiguous set of variables is shaped by domain expert recommendations. Because medicine is very important to improve the children's and older adult's health as well as reduce morality ${ }^{39-40)}$. The process design parameters of the fuzzy rule are given in table 1 with integrated examples. It ultimately works for the system's fuzzy rule base, and it helps to elevate people's livelihoods with the recommendations of a specialist valuation expert. The experts are in three specialized areas such as finance, management and electronic communication. Besides, the designer of the system is fully responsible for every stage of the system's operations.

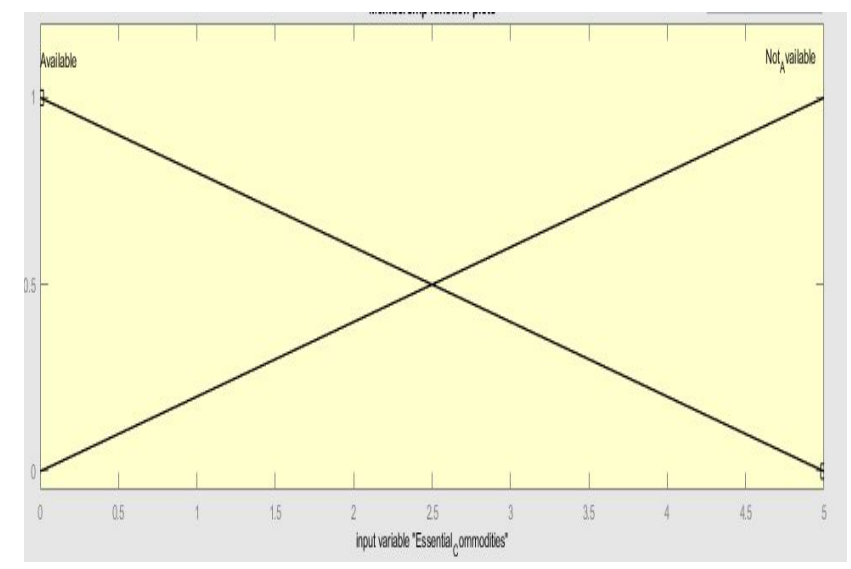

Fig. 4: Fuzzy sets of linguistic variables of Essential Commodities 


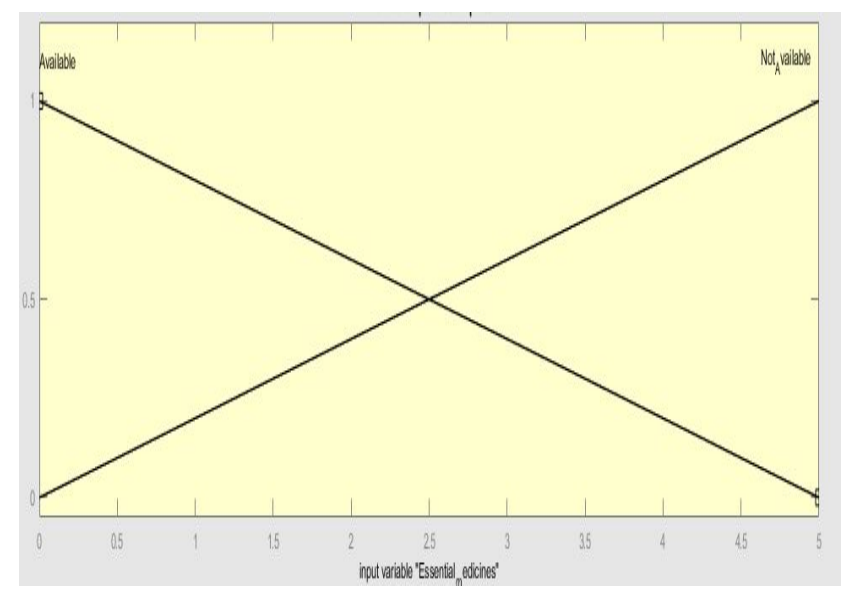

Fig. 5: Fuzzy sets of linguistic variables of Essential Medicines

The function used for the process of fuzzification of essential commodities and essential medicines variables level is triangular membership functions as given below. The available and non-available levels seem to not affect in few cases. Hence the triangular membership functions are justified. The mathematical expression of the triangular fuzzy membership function is

$$
\mu_{s}(R)=\left\{\begin{array}{c}
0, r \leq s \\
\frac{r-s}{k-s} s<r \leq k \\
\frac{q-r}{q-k} k<s<q \\
0, s \geq q
\end{array}\right.
$$

According to an earlier concept of fuzzy logic, this work variable was purely structured by its fuzzy membership functions and is often used as described in this work.

\section{Fuzzy rule base}

The livelihood of the people is very important in spreading any infectious diseases ${ }^{41)}$. In addition, essential components of people's living factors are also part of the spreading disease. After incorporating these five factors, the fuzzy rule is formulated to finally identify the causes of the disease spread and make recommendations for the epidemic. Apart from the gender if any one of the input factors is affected it has been heavily affected by the disease status. Due to this essentiality, it has been jointly connected one with each other. Therefore, according to expert recommendations on improving the livelihood of the people, fuzzy rules of formulation co-existed between $[0,1]$.
Table 1. Rule base for the proposed system

\begin{tabular}{|l|l|}
\hline Rule 1 & $\begin{array}{l}|c| \\
\text { if Essential commodities (available) and if } \\
\text { Essential medicines which for already aliment } \\
\text { diseases (available)and if Gender (Male)and if } \\
\text { Things used to take care the children as well as } \\
\text { older adult peoples (available)then diseases } \\
\text { (Spread). }\end{array}$ \\
\hline Rule 2 & $\begin{array}{l}\text { If Money (in hand) and if Essential } \\
\text { commodities (not available) and if Essential } \\
\text { medicines which for already aliment diseases } \\
\text { (available)and if Gender (Male)and if Things } \\
\text { used to take care the children as well as older } \\
\text { adult peoples (available)then diseases } \\
\text { (Spread). }\end{array}$ \\
\hline Rule 3 & $\begin{array}{l}\text { If Money (not in hand) and if Essential } \\
\text { commodities (not available) and if Essential } \\
\text { medicines which for already aliment diseases } \\
\text { (available)and if Gender (Male)and if Things } \\
\text { used to take care the children as well as older } \\
\text { adult peoples (available)then diseases } \\
\text { (Spread). }\end{array}$ \\
\hline Rule 5 & $\begin{array}{l}\text { If Money (in hand) and if Essential } \\
\text { commodities (available) and if Essential } \\
\text { medicines which for already aliment diseases } \\
\text { (available)and if Gender (Male)and if Things } \\
\text { used to take care the children as well as older } \\
\text { adult peoples (available)then diseases (Not } \\
\text { Spread). }\end{array}$ \\
\hline a \\
\hline
\end{tabular}

\section{Fuzzy Inference System}

The process of diffusion of COVID-19 depends on five factors that are labeled as money, essential commodities, essential medicines, Gender, and essential things for the orderly adults and children. As an example in essential medicines for already, aliment diseases the variable lies in the range between $0-5$ scales for both available and non-available cases. Accessing the input variables in the conditions of disease spread and not spreads are consisting into all over the world workers scenarios. The speed of disease transmission depends on the input variables and the system design perspective. The output of the system is composed of two variables, namely disease transmission and non-transmission of disease.

\section{Defuzzification}

Defuzzification provides a mathematical value for a fuzzy variable resulting from membership functions and linguistic variables. This is important when it comes to crisp value from fuzzy packages. The centroid defuzzification technique is shown below. 


$$
G=\frac{\sum_{j=0}^{u} N_{j} \mu_{s}\left(N_{j}\right)}{\sum_{j=0}^{u} \mu_{s}\left(N_{j}\right)}
$$

Where,

$$
\mu_{\mathrm{s}}=\text { membership function truth value and } \mathrm{N} \text { is the domain value of } \mathrm{j}
$$

\section{Results and Discussions}

The results and the prevalence of disease based on the assumptions of COVID-19 are directly related to social factors. Figure 6 shows that even in life-threatening moments, the importance of the human cycle is that all aspects are equally approachable and that the spread of disease events. For example, the need for money to buy essential commodities, essential medicines and child care needs and essential items for older adults is important. This can be difficult to buy in a situation where there is insufficient liquidity in the hands of the people. Conversely, even in cashless hedges, going through stores can be challenging due to a lack of production. Due to this COVID-19 epidemic, the illusion of material scarcity develops in society. In some cases, the knowledge gap between people and feelings of fear in them can sometimes be attributed to a lack of substance. But at the same time, there is only one way to make a big difference between skilled and unskilled workers. For example, skilled workers can buy with low risk on essential material factors, for which their financial background plays a particular role. They achieve it through their money-saving ability. On the contrary, unskilled workers achieve this through a state subsidy and relief package. With the help of the public distribution system in India, the government has provided people with all kinds of essentials to protect their lives ${ }^{42}$.

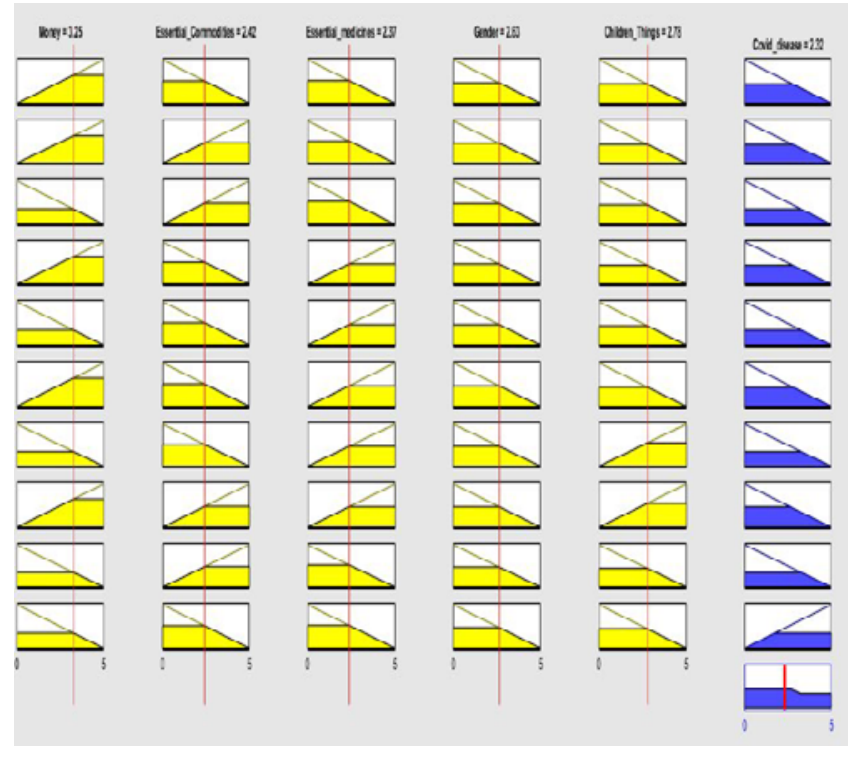

Fig. 6: Rule-based System design for COVID-19 spread
The parameters money, essential commodities, essential medicines, gender, children then COVID-19 level has been changed into depends on the skilled and unskilled workers scenarios. Therefore, the output of the designed system plays an important role in determining the extent of COVID-19 spread. In addition it has been established to be capable of making recommendations for the spread of disease. In this way, the system will be able to identify and provide appropriate recommendations to ensure that the entire essential needs of the people, including their essential livelihoods, are met with the requirements when they are susceptible to infections. The COVID-19 spread curve is flat if people encounter their life items. The state of disease transmission and non-transmission here is determined by the essential substance of the people and their cooperation. In such a life-threatening issue, the material in their hands and the cooperation between the people are both the right thing to do to prevent the speed of disease outbreak in the view of experts. It is the opinion of experts in the field that the specificity of the virus and its special features can promote the spread of the disease, but that the adoption of established preventive measures can reduce the risk of the spread of disease. Overall all the social factors are equally weightage to spread the disease to society. Comparatively, both the skilled and unskilled workers are not in the bearable situations to curb any pandemic. Thus disease like COVID-19 and some other disease has been spreading in every part of the world, there is no way to control over it, until people cooperation as well as obeying the prescribed directions announced by authorities who have closely associated with preventing and curb of the epidemic.

\section{Conclusion}

The Essential and COVID-19 outbreak fuzzy decision system has been successfully designed. The need of the system is that it is carefully designed with real-life parameters that affect people's livelihoods. Through that, all the risk factors are analyzed and it has been overcome by using a fuzzy-based decision support system. Support for system design status quo of people's life problems and related issues on the basis that real-life measurement elements can be detected. This has been successfully implemented from the point of view of the workers, such as skilled workers and unskilled workers respectively. In these infectious situations, around the world, the scientist is working hard to find a potential vaccine for the outbreak of COVID-19, the designed fuzzy decision support system providing the best structural design elements to support such an outbreak.

\section{Author Contribution}

All authors have contributed equally to the design of this work and the finalization of this paper. 


\section{Conflict of Interest}

The authors declare that there is no conflict of interest for this work.

\section{References}

1) Wu, Joseph T., Kathy Leung, and Gabriel M. Leung. "Now casting and forecasting the potential domestic and international spread of the 2019-nCoV outbreak originating in Wuhan, China: a modelling study." The Lancet 395, 689-697 (2020).

2) Wu, Fan, Su Zhao, Bin Yu, Yan Mei Chen, Wen Wang, Zhi Gang Song, Yi Hu, Zhao Wu Tao, Jun Hua Tian, and Yuan Yuan Pei. “A New Coronavirus Associated with Human Respiratory Disease in China.” Nature 579, 265-69 (2020).

3) Shi, Heshui, Xiaoyu Han, Nanchuan Jiang, Yukun Cao, Osamah Alwalid, Jin Gu, Yanqing Fan, and Chuansheng Zheng. 2020. "Radiological Findings from 81 Patients with COVID-19 Pneumonia in Wuhan, China: A Descriptive Study." Lancet Infectious Diseases 20, 425-34, (2020).

4) Song, Fengxiang, Nannan Shi, Fei Shan, Zhiyong Zhang, Jie Shen, Hongzhou Lu, Yun Ling, Yebin Jiang, and Yuxin Shi. 2020. "Emerging 2019 Novel Coronavirus (2019-NCoV) Pneumonia.” Radiology 295, 210-17, (2020).

5) World Health Organization. (2020). Coronavirus disease 2019 (COVID-19): situation report, 80.

6) $\mathrm{Xu}$, Zhe, Lei Shi, Yijin Wang, Jiyuan Zhang, Lei Huang, Chao Zhang, Shuhong Liu et al. "Pathological findings of COVID-19 associated with acute respiratory distress syndrome." The Lancet respiratory medicine 8, 420-422, (2020).

7) Walls, Alexandra C., Young-Jun Park, M. Alejandra Tortorici, Abigail Wall, Andrew T. McGuire, and David Veesler. "Structure, Function, and Antigenicity of the SARS-CoV-2 Spike Glycoprotein.” Cell, 281. (2020).

8) Fanelli, Duccio, and Francesco Piazza. "Analysis and forecast of COVID-19 spreading in China, Italy and France." Chaos, Solitons \& Fractals 134,109761, (2020).

9) Postnikov, Eugene B. "Estimation of COVID-19 dynamics “on a back-of-envelope": Does the simplest SIR model provide quantitative parameters and predictions?." Chaos, Solitons \& Fractals 135, 109841, (2020).

10) WHO Director-General's opening remarks at the media briefing onCOVID-19-11 March 2020. Available online: https://www.who.int/dg/speeches/detail/who-directo r-general-s-opening-remarks-at-themediabriefing-on -covid-19-11-march-2020 (accessed on 16 March 2020).

11) Gupta, Abhishek, Mahima Singla, Himanshu Bhatia, and Ved Sharma. 2020. "Lockdown-the Only
Solution to Defeat COVID-19." International Journal of Diabetes in Developing Countries 40,1-2, (2020).

12) Managing Epidemics key facts about major deadly diseases, World Health Organization.

13) World Health Organization, COVID-19 Virtual Press Conference- 25 March 2020.

14) 2019 Novel Coronavirus (2019-nCoV): Strategic Preparedness and Response Plan, World Health Organization.

15) Karnon, Jonathan. "A Simple Decision Analysis of a Mandatory Lockdown Response to the COVID-19 Pandemic.” Applied Health Economics and Health Policy 18,329-31,(2020).

16) McKee, Martin. “A European Roadmap out of the Covid-19 Pandemic.” BMJ 369. (2020).

17) Rao, Narasimha D., and Jihoon Min. "Decent living standards: material prerequisites for human wellbeing." Social indicators research 138, 225-244, 2018.

18) Kitjanukit, Santisak. "Attitude toward Bioremediation-Related Technology and Relation with Company Social Responsibility.” Evergreen 6, 240-45,(2020).

19) Watanabe Tomoaki. Book Review: Jessica F Green, Rethinking Private Authority: Agents and Entrepreneurs in Global Environmental Governance. Evergreen, 57-58, (2015).

20) Habib, M. D. Ahsan, K. M. Ariful Kabir, and Jun Tanimoto. 2020. “'Do Humans Play According to the Game Theory When Facing the Social Dilemma Situation?’ A Survey Study.” Evergreen 7 (1): 7-14.

21) Moroga, K., Nagata, A., Kuriyama, Y., Kobayashi, T., \& Hasegawa, K. "State of implementation of environmental and energy policies adopted by the regional governments in Japan”. Evergreen, 2, 14-23, (2015).

22) Sato, T. "How is a Sustainable Society Established? A Case Study of Cities in Japan and Germany”. Evergreen: joint journal of Novel Carbon Resource Sciences \& Green Asia Strategy, 3, 25-35, (2016).

23) Sridhar, D., \&Majumder, M. S. Modelling the pandemic Over-reliance on modelling leads to missteps and blind spots in our response. BMJ Publishing Group British, (2020).

24) Falkinger, Josef. A Theory of Employment in Firms: Macroeconomic Equilibrium and Internal Organization of Work. Springer Science \& Business Media, (2012).

25) Mello, Marcelo. "Skilled labor, unskilled labor, and economic growth." Economics Letters 100, 3, 428-431. (2008).

26) Kraft, Kornelius. "Wage differentials between skilled and unskilled workers." Review of World Economics 130, 329-349, (1994). 
27) Calvillo-King, Linda, Danielle Arnold, Kathryn J. Eubank, Matthew Lo, Pete Yunyongying, Heather Stieglitz, and Ethan A. Halm. "Impact of social factors on risk of readmission or mortality in pneumonia and heart failure: systematic review." Journal of general internal medicine 28, 269-282, (2013).

28) Ministry of finance PradhanMantriGaribKalyanYojanahttps://pib.gov.in/ PressReleaseIframePage.aspx?PRID=1608345.

29) Yadav, Vijay K., Vinod Kumar Yadav, and J. P. Yadav. "Cognizance on Pandemic Corona Virus Infectious Disease (COVID-19) by using Statistical Technique: A Study and Analysis." Evergreen 7, 329-335, (2020).

30) Krishnakumar, Balaji, and Sravendra Rana. "COVID 19 in INDIA: Strategies to Combat from Combination Threat of Life and Livelihood.” Journal of Microbiology Immunology and Infection 53 (3): 389-91. (2020).

31) Aborigo, Raymond A., Daniel D. Reidpath, Abraham R. Oduro, and Pascale Allotey. "Male Involvement in Maternal Health: Perspectives of Opinion Leaders.” BMC Pregnancy and Childbirth 18, 3, (2018).

32) Gerber, Gwendolyn L. "Leadership roles and the gender stereotype traits." Sex Roles 18, 649-668, (1988).

33) Plerou, A., Vlamou, E., \& Papadopoulos, B. Fuzzy logic models in epidemic control. Precision Medicine, 1, 1-6, (2016).

34) Massad, Eduardo, Neli Regina Siqueira Ortega, Cláudio José Struchiner, and Marcelo Nascimento Burattini. "Fuzzy epidemics." Artificial Intelligence in Medicine 29, 241-259, (2003).

35) Tamir, Dan E., Naphtali D. Rishe, Mark Last, and Abraham Kandel. "Soft computing based epidemical crisis prediction." In Intelligent Methods for Cyber Warfare, Springer, Cham, 43-67, (2015).

36) International Labour Organization, World Employment Outlook, 2019.

37) Bethune, Zachary, and Anton Korinek. "COVID-19 infection externalities: Trading lives vs. livelihoods." W27009, (2020).

38) Klebanow, Sheila, and Eugene L. Lowenkopf, eds. Money and mind. Springer Science \& Business Media, (2012).

39) Ross, Timothy J. Fuzzy logic with engineering applications. 2, New York: wiley, (2004).

40) Kazaryan, Irina, and Lusine Vardanyan. "Availability and affordability of medicines for children." Journal of Pharmaceutical Policy and Practice, 8, (2015).

41) Cartwright, Ann. "Medicine taking by people aged 65 or more." British medical bulletin 46, 63-76, (1990).
42) Krishnakumar, Balaji, and Sravendra Rana. "COVID 19 in INDIA: Strategies to combat from combination threat of life and livelihood." Journal of Microbiology, Immunology and Infection (2020). 